\title{
A VINDA DE UMA FAMÍLIA HAITIANA PARA O BRASIL SOB A ÓTICA DA TEORIA DAS REPRESENTAÇÕES SOCIAIS
}

Andressa Schuwarts Barbero ${ }^{i} \oplus 0000-0002-8679-1047$

Centro Universitário de Tecnologia e Ciências do Norte do Paraná - UniFatecie

Cleder Mariano Belierii ${ }^{i} \odot 0000-0003-0693-7235$

Centro Universitário de Tecnologia e Ciências do Norte do Paraná - UniFatecie

RESUMO: Com o crescimento do fluxo de haitianos para o Brasil, desde o terremoto de 2010 no Haiti, ocorreu um grande movimento migratório desses sujeitos para o Brasil. Desse modo, a presente pesquisa buscou discutir os motivos, desafios e consequências decorrentes dessa imigração, como eles se representavam no Haiti e como se representam agora nesse novo país. Para isso, foi realizado um estudo bibliográfico sobre a teoria das representações sociais, em Serge Moscovici, e uma entrevista semiestruturada que foi aplicada a um grupo de haitianos residentes no Estado do Paraná. Os dados coletados por meio da entrevista demonstraram o impacto dessa imigração no Brasil, por meio da geração de conflitos entre a representação social de haitianos e brasileiros, ocasionando indiferença social e preconceitos. Aposta-se que a indiferença e os preconceitos entre brasileiros e haitianos podem ser superados por mudanças em suas representações sociais.

PALAVRAS-CHAVES: Haitianos. Brasil. Representações Sociais.

\section{THE COMING OF A HAITIAN FAMILY TO BRAZIL FROM THE POINT OF VIEW OF THE THEORY OF SOCIAL REPRESENTATIONS}

\begin{abstract}
With the growth of the flow of Haitians to Brazil, since the 2010 earthquake in Haiti, there was a great migratory movement of these subjects to Brazil. In this way, the present research sought to discuss the reasons, challenges and consequences arising from this immigration, how they represented themselves in Haiti and how they now represent themselves in this new country. For this, a bibliographical study on the theory of social representations was carried out, in Serge Moscovici, and a semi-structured interview that was applied to a group of Haitians living in the State of Paraná. The data collected through the interview demonstrated the impact of this immigration in Brazil, through the generation of conflicts between the social representation of Haitians and Brazilians, causing social indifference and prejudices. We bet that indifference and prejudice between Brazilians
\end{abstract}

and Haitians can be overcome by changes in their social representations.

KEYWORDS: Haitians. Brazil. Social Representations. 


\section{Introdução}

O presente artigo discute os motivos, desafios e as consequências decorrentes da imigração de uma família haitiana para o Estado do Paraná. Para isso, inicialmente discorreremos, de forma breve, sobre as condições vividas pelos haitianos antes de chegarem no Brasil. Logo após, apresentaremos a compreensão sobre as representações sociais, como base no estudo de Serge Moscovici $(1999 ; 2011)$, mostrando como ela se forma e é transmitida no interior dos grupos socais. Essa compreensão serviu de base para entender e analisar como tem sido representada a chegada de haitianos em um Município do Estado do Paraná e como eles têm representado as condições vividas nesse Estado. Na terceira parte apresentaremos os dados coletados de uma experiência de imigração vivida por uma família haitiana residente no estado do Paraná, por meio de uma entrevista semiestruturada, que foi analisada por meio da Teoria das Representações Sociais.

\section{Uma leitura histórica do Haiti}

Desde a proclamação da independência em 1804, o Haiti entre os países mais pobres da América, padecente da progressão de ditadores. No ano de 1957, estava à frente da presidência o Sr. François Duvalier, mais conhecido como "Papa Doc", eleito mediante ao reboliço político, - seis governos tinham tomado posse no período de dez meses, logo após a retirada forçada do ditador Paul Magloire. Em 14 anos de governo, Duvalier se tornou o ditador mais aterrorizante do país, tendo destaque como o patriarca mais sanguinário e macabro de todos.

No ano de 1971 o presidente Papa Doc, vem a óbito e seu filho, JeanClaude Duvalier (Baby Doc), sucede seu pai na presidência do Haiti até 1986. Durante o seu governo a taxa de analfabetismo subiu drasticamente, a perspectiva de vida era baixa e havia epidemias de fome e Aids por todo país. Em 1990 Jean-Bertrand Aristide é eleito como mandatário do Haiti. Mas, com a descoberta de um golpe de estado, Aristide vai embora do país, retornando somente em 1994 com o apoio de militares comandados pelos Estados Unidos da América (EUA). Somente em 2000, Jean-Bertrand assume o posto de presidente do país, burlando os votos da eleição. Ao negar os problemas decorridos da eleição à oposição rejeitou sua presidência, consequentemente a revolta se expandiu por todo o Haiti em um curto período. Com isso, vários haitianos saíram do país, deixando os Estados Unidos e a França furiosos com essa imigração. 
DOI 10.33872/revcontrad.vlnl.e006 | v. 1, n. 1 | Jan./Jun. 2020

O governo de Jean-Bertrand termina em 2004 suprimido a força por militares comandados pelos EUA, apoiados pela França, deixando o país mais debilitado e com imensa desigualdade social, baixo desenvolvimento humano, violência e uma política instável. Os problemas socioeconômicos do país foram agravados com um terremoto, em 12 de janeiro de 2010, com registro de grau 7 na escala Richter, considerado "muito forte". Os tremores contribuíram ainda mais para a destruição do país, afetando hospitais, escolas, postos policiais, residências e demais postos de atendimento à população. Morreram mais ou menos de $150 \mathrm{a}$ 200 mil mortos, sendo três milhões de pessoas atingidas pelo abalo sísmico - quase um terço de toda a população.

Foram desenvolvidos com a assistência internacional, fruto do Acordo Básico de Cooperação Técnica e Científica entre o Governo da República Federativa do Brasil e o Governo do Haiti. Na prevenção de combate no trabalho infantil, criou-se a OIT - Cooperação Técnica para Proteção de Crianças contra o Trabalho Infantil -. Para o levantamento geral do Haiti originou a UNFPA - Cooperação Técnica para Apoio ao V Recenseamento Geral de População e Habitação no Haiti -. Com o propósito de fortalecer o sistema de saúde e da vigilância epidemiológica surgiu o PNUD - Fortalecimento da Autoridade Sanitária do HAITI(implementado no âmbito do Acordo Tripartite Brasil-Haiti-Cuba). Dentre vários outros projetos disponibilizados para o país. Mas por que os haitianos escolheram o Brasil para imigrarem?

A hipótese inicial era a de que tínhamos como ponto de partida para a questão apresentada era a de que população haitiana estaria representando a imigração para o Brasil como condição para uma melhor qualidade de vida, independente dos contingentes econômicos e sociais e das normas jurídicas, o que se pretendia eram condições de sobrevivência por meio do trabalho (HOBSBAWM, 2000). Essa hipótese fundamenta-se no fato o Brasil estar na frente do comando encontrava-se o Brasil, com ajuda de tropas militares de outros 15 países, com a finalidade, por meio de uma iniciativa da ONU (Organização das Nações Unidas) a MINUSTAH (Missão de Paz das Nações Unidas para o Haiti), trazer a paz para o Haiti, buscando restaurar a segurança e a estabilidade do país. Assim, partimos do pressuposto de que as interações sociais ocorridas entre os haitianos e os brasileiros teriam contribuído para que os haitianos formassem uma representação do Brasil como um local com maiores e melhores condições materiais e sociais para sobreviverem.

A fim de colocarmos a prova a nossa hipótese inicial e a questão que gerou a necessidade dessa investigação fomos buscar na Teoria das Representações Sociais instrumentos para uma compreensão mais ampla e profunda sobre o movimento imigratório de haitianos para o Brasil 
DOI 10.33872/revcontrad.vlnl.e006 | v. 1, n. 1 | Jan./Jun. 2020

e, sobretudo, para o Estado do Paraná. Esse referencial teórico tem, na contemporaneidade, subsidiado inúmeras pesquisas que buscam entender representações sociais de gênero, étnicas e religiosas e o impacto dessas representações na vida humana. Por esse motivo acreditamos que também poderia contribuir para uma reflexão qualitativa sobre a imigração de haitianos para o Estado do Paraná.

\section{A Teoria das representações sociais}

Como já foi mencionado, para compreender os motivos sociais que trouxeram os haitianos para o Brasil, fomos buscar apoio na Teoria das Representações Sociais, conforme apresentada por Serge Moscovici. Para o autor, a realidade da "vida cotidiana é influenciada pela comunicação pela qual os indivíduos se ligam entre si” (MOSCOVICI, 1999; 2011), adquirindo a capacidade de se unirem ou se afastarem de outras pessoas.

No desenvolver do estudo das representações sociais, Serge Moscovici retomou os estudos de Emile Durkheim, foi à Psicologia Social individualista, porém, não levou em consideração tudo o que a representação durkheimiana apresentava. Durkheim, tinha como objeto principal de estudos o fato social, que ele define como "[...] toda a maneira de fazer, fixada ou não, suscetível de exercer sobre o indivíduo uma coação exterior, que é geral no conjunto de uma dada sociedade tendo, ao mesmo tempo, uma existência própria, independentemente de suas manifestações individuais" (DURKHEIM, 1973, p. 394), ou seja, o fato social é imposto para os indivíduos, não dependendo deles, mas exercendo uma força sobre eles.

Considerando que a sociedade possuía o seu próprio gênero, Durkheim, estipulou que cada determinada sociedade possuí um tipo de "consciência coletiva que mantem a coesão social" (DURKHEIM, 1973), sendo essa consciência tipos de representações coletivas do pensamento, como o modo de agir, crenças religiosas, entre outros. Moscovici buscava uma "Psicologia Social" (MOSCOVICI, 2011), no qual, o conhecimento é elaborado através da comunicação, transformando e projetando o mundo social. Portanto, seu principal objeto de estudo fixou no que ele denominou como representações sociais, tratando-se de elementos praticamente palpáveis, que participavam do cotidiano de cada pessoa, seja no trabalho, nas conversas, na escola, ou em outros lugares.

Mas, o conceito de representação social é árduo para ser entendido, no qual Moscovici vai dizer: 
DOI 10.33872/revcontrad.vlnl.e006 | v. 1, n. 1 | Jan./Jun. 2020

[...] Há muitas boas razões pelas quais isso é assim. Na sua maioria, elas são históricas e é por isso que nós devemos encarregar os historiadores da tarefa de descobri-las. As razões não históricas podem todas ser reduzidas a uma única: sua posição "mista", no cruzamento entre uma série de conceitos sociológicos e uma série de conceitos psicológicos. É nessa encruzilhada que nós temos de nos situar. O caminho, certamente, pode representar algo pedante quanto a isso, mas nós não podemos ver outra maneira de libertar tal conceito de seu glorioso passado, de revitalizá-lo e de compreender sua especificidade (MOSCOVICI, 2011, p. 40-41).

Nesse sentido, Moscovici entendia que a representação social (RS) era um estudo psicosociológico, com uma relação simultânea entre individual e social. O que na teoria anterior a representação social era considerada como um conceito, agora com outra perspectiva, é considerada como um fenômeno que se manifesta entre os sujeitos. Com isso, as representações coletivas de Emile Durkheim parecem serem incorporadas e ampliadas na concepção de representação social de Serge Moscovici, cuja sua função, em uma forma mais reduzida de conhecimento é estudar os comportamentos e a comunicação dos e entre os sujeitos, “[...] pois pelo fato de querer incluir demais, inclui-se muito pouco: querer compreender tudo é perder tudo.' (MOSCOVICI, 2011, p. 46)

Por seguinte, Moscovici levou a teoria das representações sociais (RS) a estudar como as coisas na sociedade mudam e situar a Psicologia e as Ciências Sociais como uma dupla natureza, que respectivamente as manifestações dos fenômenos sejam caracterizadas por elas. Assim, com suas próprias palavras Moscovici, diz sobre a posição que as RS ocupam: “[...] posição mista na encruzilhada de uma série de conceitos sociológicos e de conceitos psicológicos"' (MOSCOVICI, 2011, p. 39).

Assim, a partir do exposto, pode-se inferir que enquanto as representações clássicas tratavam a organização cognitiva como um componente imóvel, as representações sociais a consideram como uma relação dualista entre o processo cognitivo e a estrutura cognitiva, com o objetivo funcional das próprias representações, que na afirmação de Moscovici: “o propósito de todas as representações é tornar algo não familiar, ou a própria não familiaridade, familiar' (MOSCOVICI, 1999; 2011). Ou seja, aquilo que não era conhecido se enquadrada no mundo familiarizado/conhecido do indivíduo.

Além disso, Moscovici deixa três pontos importantes sobre as representações sociais. Primeiro, uma representação social não define fielmente uma realidade, pois de acordo com o contexto que a pessoa está inserida influenciará a criar realidades e não apenas espelhá-las. Karl Marx, também vai dizer sobre essa ilusão criada pelos indivíduos, no qual teve um sentido ideológico, em que a ideia não condiz com a realidade. Marx diz: 
[...] na produção social de sua vida, os homens contraem determinadas relações necessárias e independentes de sua vontade, relações de produção que correspondem a uma determinada fase de desenvolvimento de suas forças produtivas materiais. [...] O modo de produção da vida material condiciona o processo de vida social, política e espiritual em geral. Não é a consciência do homem que determina seu ser; pelo contrário, é o ser social que determina sua consciência (MARX, 1983, p. 24, edição original 1859).

Acontecendo dentro da crítica capitalista Marx, fundamenta a importância da compreensão do modo de produção para entender como os indivíduos se organizam no funcionamento de uma sociedade. Assim, a sociedade transpassa à consciência do sujeito uma ideia no sentido neutro, para defender algo que ela estipulou como correta, mesmo que não vá de acordo com a verdadeira realidade.

Segundo Moscovici, muitas "coisas que são consideradas verídicas podem se tornar ilusões futuras" (MOSCOVICI, 1999), pois as representações sociais estabelecidas podem perder o seu sentido e dar lugares para outros. Não existindo uma única representação de mundo, no qual essa definirá piamente todas sociedades existentes, levando em consideração que existem diferentes grupos, diferentes culturas, diferentes formas de viver, entre outros presentes no mundo.

A percepção de mundo e de pessoa vão de acordo com as respostas recebidas dos estímulos pelo ambiente inserido. Porém, não se é tomado consciência de várias coisas que estejam diante dos olhos, tornando-se em um sentido figurado, invisíveis. Determinantes subdividem as pessoas em categorias preestabelecidas da realidade, fazendo com que os indivíduos sejam vistos, ou não, pelos demais de outras classes. Esse convencimento de fatos aceitos pela sociedade cria ilusões percentuais à aparência, através de uma noção ou imagem pronta concebida. Sendo assim, a forma de representação sobre algo ou alguém, está relacionada com o ambiente em que se está inserido socialmente. Nesse contexto, Frege diz:

\footnotetext{
A influência de uma pessoa sobre outra acontece principalmente através do pensamento. Alguém comunica um pensamento. Como acontece isso? Alguém causa mudanças no mundo externo normal que, percebidas por outra pessoa, são consideradas como induzindo-a a apreender um pensamento e aceitá-lo como verdadeiro (FREGE, 1977, p. 38).
}

Assim, uma representação social é um fenômeno que concede significado a percepção de mundo, proporcionando a toda imagem uma ideia e toda ideia a uma imagem, servindo também de suporte para esses princípios. Sendo de tal modo, construtiva em experiências e 
comportamentos em grupo, partindo do abstrato para a realidade e senso comum. No momento que a sociedade é subdividida por classes e pela ocupação que cada indivíduo particular ocupa no meio, os cidadãos se tornam desiguais entre si, cujo seu nível de participação será determinado pela sua classificação (MOÑIVAS LAZARO, 1993). Nesse sistema preestabelecido os indivíduos ficam pregados em um 'acerto' geral, pela não compreensão mútua. Portanto, as representações sociais se voltam para a imagem coletiva que se tem, de algo ou alguém, para a percepção e para a comunicação. Moscovici argumenta sobre a representação social:

Um sistema de valores, ideias e práticas, com uma dupla função: primeiro, estabelecer uma ordem que possibilitará às pessoas orientar-se em seu mundo material e social e controlá-lo; e, em segundo lugar, possibilitar que a comunicação seja possível entre os membros de uma comunidade, fornecendo-lhes um código para nomear e classificar, sem ambiguidade, os vários aspectos de seu mundo e da sua história individual e social (MOSCOVICI, 2011, p. 12).

Para Moscovici, a formação da representação social acontece por dois processos, "a ancoragem e a objetivação" (MOSCOVICI, 2011). Quando algo ou ideia estranha chega o primeiro mecanismo para dar a feição familiar é a ancoragem, essa ideia estranha será desmembrada e ajustada a categorias e a imagens comuns já existentes, sendo comparada e alcançada a suas características para familiarizar ao modelo protótipo da categoria, voltando-se para posições já existentes e precipitadas. Nesta classificação é estipulado o que se pode, ou não, ocorrer entre os indivíduos do mesmo conjunto de acordo com o seu modelo, formando a relação positiva ou negativa (MOÑIVAS LAZARO, 1993).

Com isso, é impossível deixar de dar nomes para incluir a outras ideias e imagens, pois "o anonimato é confuso e incomunicável" (MOSCOVICI, 2011). Moscovici fala sobre a denominação:

Podemos até mesmo ir ao ponto de sugerir que essa [denominação] é a maneira como todas as manifestações normais e divergentes da existência social são rotuladas - indivíduos e grupos são estigmatizados, seja psicológica, seja politicamente. Por exemplo, quando nós chamamos uma pessoa, cujas opiniões não estão de acordo com a ideologia corrente, de um "inimigo do povo", o termo que, de acordo com aquela ideologia, sugere uma imagem definida, exclui essa pessoa da sociedade à qual ela pertence. É, pois, evidente que dar nome não é uma operação puramente intelectual, com o objetivo de conseguir uma clareza ou coerência lógica. É uma operação relacionada com uma atitude social (MOSCOVICI, 2011, p. 68).

A partir do momento que se é nomeado algo ou alguém é possível construir particularidades, separando do meio de outros objetos ou pessoas, participando dos demais com 
DOI 10.33872/revcontrad.vlnl.e006 | v. 1, n. 1 | Jan./Jun. 2020

as mesmas características, pois “[...] os que falam e os de quem se fala são forçados a entrar em uma matriz de identidade que eles não escolheram e sobre a qual eles não possuem controle." (MOSCOVICI, 2011, p. 68). Torna-se claro, assim, que nesse mecanismo de ancoragem, as classificações e denominações são essenciais para a representação social.

Levando em consideração que uma nova ideia só será construída a partir de outras já presentes, sendo modificadas juntamente com o que será representado para possuir uma nova existência, pode-se dizer um exemplo simples de ancoragem, como: a promoção dos vendedores sobre os seus produtos, colocando um preço elevado como base para o cliente, podendo depois dar um desconto para se chegar ao seu desejo de venda. A partir do momento que o consumidor recebe um valor menor do produto, ele assimila que o valor anterior é bem maior do que está agora, sentindo-se satisfeito efetua a compra.

Em segundo lugar, a objetivação vem movendo a ideia abstrata para o real, para ao que já existia no mundo, ligando palavras para formar um conceito sob a imagem desejada, com isso imediatamente o que era invisível se torna perceptivo mentalmente. Moscovici descreve:

[...] objetivar é descobrir a qualidade icônica de uma ideia, ou ser impreciso; é reproduzir um conceito em uma imagem. Comparar é já representar, encher o que está naturalmente vazio com substância. Temos apenas de comparar Deus com um pai e o que era invisível, instantaneamente se torna visível em nossas mentes, como uma pessoa a quem nos podemos responder como tal (MOSCOVICI, 2011, p. 71-72).

Portanto, a objetivação faz a união entre a não familiaridade e a realidade, ocorrendo a passagem do mundo inteiramente intelectual para o mundo possivelmente físico e acessível por meio da absorção de vários significados, caracterizando a estrutura do conhecimento. Porém, essa ligação de palavras em imagens não é generalizada, simplesmente por não ter a quantidade de imagens suficientes ou por estarem restritas, se embaralhando em um conjunto de figuras formando consequentemente, um emaranhado de ideias.

Com o estoque de imagens possuídas e com as crenças já existentes, o que menor for sofrerá a repressão sobre o mais alto que dará origem aos complexos, deste modo, a preferência da sociedade decidirá qual modelo adotar, levando em consideração que essa escolha movera à aceitação pela analogia de esquemas mais modernos. Moscovici afirma que embora um paradigma seja aceito porque ele possui um forte referencial, sua aceitação deve-se também à sua afinidade com paradigmas mais atuais. A concretude dos elementos desse sistema psíquico “deriva de sua capacidade de traduzir situações comuns” (MOSCOVICI, 2011; 1976). 
A partir do momento que o padrão é aprovado socialmente, tudo que esteja conectado a ele se torna muito comunicativo como também, uma ferramenta para compreender outros e a si próprio. Fazendo um paralelo aos estudos de Leontiev, ele vai argumentar que "o homem só se humaniza pela apropriação da cultura" (LEONTIEV, 2004), sendo esta uma aquisição ou transformação de algo, na qual se dará pelo processo de comunicação entre o homem por meio da linguagem, em que é um instrumento psicológico interno, portanto, esse instrumento simbólico permitirá a relação social entre as pessoas do grupo. Essa apropriação da cultura é determinada e determina a sociedade pelo o processo do trabalho educativo. Dermeval Saviani, diz:

O trabalho educativo é o ato de produzir direta e intencionalmente, em cada indivíduo singular, a humanidade que é produzida histórica e coletivamente pelo conjunto dos homens. Assim, o objeto da educação diz respeito, de um lado, à identificação dos elementos culturais que precisam ser assimilados pelos indivíduos da espécie humana para que eles se tornem humanos [...] (SAVIANI, 2003, p.13).

Entende-se a educação como um trabalho educativo, constituindo como um fenômeno próprio do ser humano, no qual o homem se humaniza. Com o trabalho transformam-se o cérebro, os órgãos de atividade externa e os órgãos dos sentidos. Leontiev, evidencia que "o trabalho criou o homem e a sua consciência" (LEONTIEV, 2004), e quando o indivíduo transforma o conhecimento em objeto ele objetiva esse conhecimento em realidade.

Porém, quando essa realidade é separada de sua origem, torna-se livre à uma realidade habitual, sendo tomada como um fato convincente na sociedade, ou seja, a imagem estabelecida do padrão deixa de ser o significado e vem a ser uma imitação da realidade. No qual, Moscovici vai dizer:

A imagem do conceito deixa de ser um signo e torna-se a réplica da realidade, um simulacro, no verdadeiro sentido da palavra. A noção, pois, ou a entidade da qual ela proveio, perde seu caráter abstrato, arbitrário e adquire uma existência quase física, independente (MOSCOVICI, 2011, p. 74).

"Todas as imagens tem consigo uma realidade, independente de qual for" (MOSCOVICI, 2011), quando se é dado significado a elas deixam de ser fragmentos do pensamento e tornam-se fragmentos da própria realidade e suas características próprias revertem as características dos fenômenos, o que antes era um sentido abstrato que a respectiva pessoa atribuía, agora encontram-se como objetos significativos. 
Nosso ambiente é formado por imagens e, consequentemente, por representações da realidade. Com isso, cada cultura em si utiliza de suas próprias ferramentas para objetivar tudo o que venha à sua frente, não possuindo uma única ferramenta, mas, variando de acordo com os objetos em questão, ou seja, aquela que mais se encaixar no contexto do problema incentivará em sua objetivação. Para essa personificação ocorrer o mediador se tornará a própria linguagem, que transformará os atributos em ações e, representando e criando as ações com suas peculiaridades. Moscovici argumenta:

[...] a conversação (os discursos) cria nós de estabilidade e recorrência, uma base comum de significância entre seus praticantes. As regras dessa arte mantêm todo um complexo de ambiguidades e convenções, sem o qual a vida social não poderia existir. Elas capacitam as pessoas a compartilharem um estoque implícito de imagens e de ideias que são consideradas certas e mutuamente aceitas. O pensar é feito em voz alta. Ele se torna uma atividade ruidosa, pública, que satisfaz a necessidade de comunicação e com isso mantém e consolida o grupo, enquanto comunica a característica que cada membro exige dele (MOSCOVICI, 2011, p. 51).

Essa conversação envolverá o indivíduo com os demais da sociedade, produzindo um conforto entre eles para se relacionarem, no qual compartilharam diversas ideias que socialmente foram aceitas. $\mathrm{O}$ que antes era somente um pensamento, algo abstrato, agora se consolida em ações praticadas verbalmente por todos do mesmo grupo.

\section{Encaminhamento metodológico}

Conforme o que foi exposto até aqui, elaboramos uma entrevista que foi feita com Victor (nome fictício), no dia 30 de agosto de 2019. Haitiano que veio para o Brasil em 17 de abril de 2015, residente na cidade de Paraíso do Norte - Paraná, com sua esposa e seus cinco filhos. No momento, somente Victor trabalha para sustentar a sua família.

Assim, lançamos mão de pesquisas bibliográficas, o estudo sobre as representações sociais e uma entrevista semiestruturada com uma família haitiana. A entrevista foi realizada no dia 30 de agosto de 2019, com uma família haitiana que vieram para o Brasil, em 17 de abril de 2015, e estão atualmente residentes na cidade de Paraíso do Norte - Paraná. Abaixo estão os dados coletados, organizados em quatro unidades de análise, que foram apresentadas à família de haitianos sobre a forma de questões: Motivações recebidas para a vinda ao Brasil; Impactos com a chegada ao Brasil; Representação sobre o Haiti; Representação sobre o Brasil. 
DOI 10.33872/revcontrad.vlnl.e006 | v. 1, n. l| Jan./Jun. 2020

Entrevista Semiestruturada: Família Haitiana.

\begin{tabular}{|c|l|}
\hline \multicolumn{1}{|c|}{ Questões } & \multicolumn{1}{c|}{ Respostas } \\
\hline $\begin{array}{c}\text { Motivações recebidas para a vinda } \\
\text { ao Brasil }\end{array}$ & $\begin{array}{l}\text { Adquirir uma vida melhor, pois em 2010 } \\
\text { aconteceu o terremoto no Haiti que destruiu, } \\
\text { praticamente todo o país. Assim, o presidente } \\
\text { comunicou a todos que fossem embora para } \\
\text { o Brasil, porque lá as portas estavam } \\
\text { abertas... Os soldados brasileiros foram } \\
\text { muito solícitos com a população haitiana. }\end{array}$ \\
\hline Impactos com a chegada no Brasil & $\begin{array}{l}\text { Os impactos foram de grande dificuldade, } \\
\text { estranhos em meio à sociedade, possuindo } \\
\text { outra cultura, comportamento, linguagem, } \\
\text { entre sociais, preconceitos e outras } \\
\text { diferenças. }\end{array}$ \\
\hline Representação sobre Haiti & $\begin{array}{l}\text { No Haiti as coisas dependem muito de que } \\
\text { pessoa você é ou não, de que família você } \\
\text { nasceu, onde você mora e onde estuda. Não } \\
\text { sendo da classe 'superior', a vida era de } \\
\text { inferioridade, insegurança, amedrontamento, } \\
\text { instabilidade, entre outros problemas. }\end{array}$ \\
\hline Representação sobre Brasil & $\begin{array}{l}\text { Diferentemente, de como vivíamos no Haiti, } \\
\text { hoje no Brasil somos vistos como diferente } \\
\text { aos demais, mas, possuindo um pouco mais } \\
\text { de auxílio a saúde, segurança, educação etc. }\end{array}$ \\
\hline
\end{tabular}

Fonte: Andressa Schuwarts Barbero, 2019.

\section{Análise dos dados levantados}

Após a apresentação dos dados acima, por meio da realização do contexto histórico, pelo estudo das representações sociais e da entrevista com a família de haitianos, pode-se inferir que o Haiti se encontra a muito tempo martirizado por causa da má política dos governos que administravam o país e pelas grandes epidemias de fome e Aids, tornando-se comuns no seu meio pois, já sofriam com a falta de segurança, com o analfabetismo e com a desigualdade social.

Para agravar ainda mais a situação que os haitianos se encontravam, os desastres naturais do terremoto (ocorrido em 2010) e do furacão Mattew (ocorrido em 2016) contribuíram ainda mais para a destruição do país. É evidente que as pessoas que estavam vivendo todo esse sofrimento almejavam uma vida melhor, em outras palavras, um começo mais digno de se viver, no qual, todos esses fatores motivaram os haitianos a imigrarem para o Brasil. Mas, qual foi o impacto que os haitianos tiveram em sua vida com essa mudança? Ou até mesmo, como eles se representavam no Haiti e como eles se representam agora no Brasil? 
Como foi dito por Moscovici, uma representação social é uma imagem preestabelecida de algo, de que tal modo dará significado as percepções do meio em que a pessoa se encontra e como ela se comporta em grupo. Assim:

[...] as representações sociais sempre se preocuparam com os aspectos da sensibilidade social, sentimentos sociais, entre outros. [Elas] são indispensáveis para mobilizar as pessoas, para permitir representar o futuro e também para criar vínculos, uma vez que há algo posto em comum com o pensamento, nos sentimentos e no intercâmbio conversacional. (MOSCOVICI, 1999, p. 302-303, grifo aposto).

Com essa representação o indivíduo recebe uma orientação com valores, ideias e práticas de como inteirar-se no social e no seu individual, permitindo a comunicação com as demais pessoas do mesmo grupo. Essa orientação, ou podendo dizer regras, enquadrará a cada situação um comportamento.

A maneira de como os haitianos se encontravam no país de origem, seja seu ambiente, sua cultura, ou como se comunicavam, deu suporte para receberem representações as quais deveriam se enquadrarem. Sendo divididos e classificados em categorias hierárquicas econômicas, a maioria não possuía segurança para suas casas, não possuíam estudos para seus filhos e muito menos auxílio a saúde. Claro, que aqui não se pode desconsiderar de como o governo tem falhado em sua função com a população, mas, como isso já era estabelecido em sua sociedade os tornavam presos a essas organizações elitizadas e faziam delas familiares a sua realidade. Quando essa familiaridade é aceita, sua representação se torna um hábito no meio da população, seja para os de classes "superiores", ou para os menos favorecidos (MOÑIVAS LAZARO, 1993), como podemos constatar nas palavras do haitiano Victor.

Com a carência de condições de vida melhores, a imigração era apresentada a eles como uma possível solução dos seus problemas e uma possível qualidade de vida. Mas, quando chegam no Brasil as coisas mudam de contexto, a comunicação com os brasileiros torna-se um fator de grande dificuldade, pois as linguagens se divergem uma da outra, os hábitos de cultura mudam, o que antes era correto se fazer diante de um problema, hoje já não se encaixa mais, visto que "o cenário mudou e que precisam aprender essa nova realidade" (MOSOCVICI, 2011). Essa não familiaridade entre o abstrato de concepções da sua mente com a realidade concreta, transpõem aos haitianos confusões de como se comportarem em grupo, apresentando diversas dificuldades como apresenta Victor.

Essa mesma situação acontece com os brasileiros em relação aos haitianos. Sendo os dois de comunidades diferentes vivendo em uma única, carregando consigo um desconforto pela diferença de ambos, por de fato não se encaixarem as categorias já existentes. Sua presença 
DOI 10.33872/revcontrad.vlnl.e006 | v. 1, n. 1 | Jan./Jun. 2020

é percebida pelos brasileiros, mas, de certa forma rejeitada, pelo amedrontamento da desordem social. Simplificando, pode-se dizer que sabemos que eles vivem entre nós, que participam das rotinas de trabalho, estudam nas mesmas escolas e que vão se agregando a comunidade, porém, não os aceitamos como iguais a nós pelas suas diferenças. Desse modo, a representação sobre eles é de indiferença ao que já é comum no meio do grupo, "gerando preconceitos explícitos ou não sobre eles" (MOSCOVICI, 1999; 2011).

Entretanto, ao entrevistar a família haitiana, fomos capazes de perceber que a sua representação e de sua família aqui no Brasil é "fixada ao seu sistema de ancoragem" (MOSCOVICI, 1999; 2011). Explicando melhor, a principal função desse sistema que todos nós possuímos é criar uma ideia nova a partir de uma outra já existente, o novo se torna realidade por estar apoiado ao velho. Como ele mesmo disse 'nosso principal motivo de estarmos aqui é conseguir viver melhor do que estávamos antes', tomando isso como justificativa ao argumento apresentado, a sua percepção de vida e relacionamento aqui no Brasil, está extremamente ligada pela comparação de como eles se encontravam no Haiti - onde viviam amedrontados pela insegurança, pela falta de alimentos em sua mesa, por não possuírem o mínimo de saúde e por serem abalados ainda mais com os desastres naturais - e de como eles se encontram agora no Brasil, não sendo prejudicados por destruições e possuindo um pouco mais de dignidade.

Mesmo que o Brasil não proporcione as devidas condições básicas e suplementares para a população viver, e que a comunidade não os veja como iguais entre os demais, ainda assim, categorizam o Brasil como melhor que seu país de origem, pelo fato de estarem ancorados ao seu passado.

\section{Conclusão}

De acordo com o que foi estudado através de autores já mencionados, pesquisas bibliográficas e uma entrevista uma família de haitianos, chega-se à conclusão que o principal impacto desse contexto da imigração dos haitianos para o Brasil, tomando como base as representações sociais, é o enquadramento de uma nova realidade em um diferente ambiente e suas consequências dessa nova mudança. Em primeiro, quando chegam aqui são confrontados pela não familiaridade, suas concepções, ideias e valores dificilmente se encaixam no meio do grupo brasileiro. Eles são comparados ao modelo protótipo que a comunidade designou como certo, classificando-os como indiferentes aos demais.

Com base no estudo realizado até aqui, podemos dizer que a hipótese inicial que tínhamos como ponto de partida para a questão apresentada neste manuscrito encontra a sua 
DOI 10.33872/revcontrad.vlnl.e006 | v. 1, n. 1 | Jan./Jun. 2020

confirmação nas palavras apresentadas pelo haitiano Victor de que o Brasil ofereceria condições para uma melhor qualidade de vida social e econômica, contudo, como ele mesmo apresentou, a desigualdade social, cultural, o preconceito, a discriminação e a desigualdade econômica se fazem objetivadas de forma estrutural entre os sujeitos tanto no Brasil como no Haiti. Esse fato coloca em questão a representação social que ele possuía sobre o Brasil, a partir da sua experiência histórico-social no Estado do Paraná.

Queremos destacar que para ocorrer à superação de indiferença e do preconceito entre haitianos e brasileiros as representações sociais devem ser alteradas, juntamente com objetivação das características que são comuns a ambos. Para isso há necessidade, como base no pensamento de Marx $(1978 ; 1984 ; 2002)$, que a base material e histórica que sustentam essas representações seja analisada, incorporadas e superadas.

\section{REFERÊNCIAS:}

FREGE, Gottlob. Traslations from the Philosophical Writtings of Gottlob Frege. Oxford: Basil Blackwell, 1977.

DURKHEIM, Émile. Sociologia e Ciências Sociais. Trad. Inês D. Ferreira. São Paulo: DIFEL, 1975.

LEONTIEV, Alexei. O desenvolvimento do psiquismo. Lisboa: Livros Horizonte, 1978.

HOBSBAWM, Erick. Mundos do trabalho. $3^{\text {a }}$ ed. São Paulo: Paz e Terra, 2000.

MARX, Karl. A questão judaica. São Paulo: Centauro: 2002.

MARX, Karl. Acerca Del colonialismo. Madrid: Ediciones Jucar, 1978.

MARX, Karl. O Capital: crítica da economia política. Vol. I, Tomo 2 (Col. Os Economistas). São Paulo: Abril Cultural, 1984.

MARX, Karl. "The 'first' draft". In: SHANIN, T. (org.). Late Marx and the Russian road: Marx and "the peripheries of capitalism". New York: Monthly Review Press, 1983.

MOSCOVICI, Serge. Lo social em tiempos de transición (Entrevista concedida a Mireya Losada), Venezuela, SIC, n. 617, pp. 302-305, ago./1999.

MOSCOVICI, Serge. A representação social da psicanálise. Rio de Janeiro: Zahar: 2011.

MOÑIVAS LAZARO, A. Las representaciones sociales. In: NAVÁLON VILA, C. \& TORNERO, M. E. M. et all. Psicología y trabajo social. Barcelona: Promociones y Publicaciones Universitarias (Colección Maior, 18), 1993.

SAVIANI, Dermeval. Pedagogia histórico-crítica: primeiras aproximações. $8^{\mathrm{a}}$ ed. Campinas, SP: Autores Associados, 2003.

IMDH. Migração haitiana para o Brasil. Disponível em: https://www.migrante.org.br/migracoes/migracao-haitiana/migracao-haitiana-para-o-brasil/ Acesso em: 23 de junho de 2019. 


\footnotetext{
${ }^{\text {i }}$ Acadêmica do curso de graduação em Psicologia (UniFatecie). Email: andressaschuwarts.17451@ @atecie.edu.br ii Doutor em Educação (UEM), professor do Magistério da Rede Estadual de Ensino do Estado do Paraná e do curso de Psicologia da UniFatecie. Email: bellieri@gmail.com
} 